\title{
Beyond the unmeasured anions: the clinics
}

\author{
Chiara Lazzeri · Serafina Valente • \\ Gian Franco Gensini
}

Received: 27 February 2010/Accepted: 26 March 2010/Published online: 22 April 2010

(C) SIMI 2010

We thank Dr Berend for his kind suggestions. Beyond the discussion and comparison between different types of fruits, the aim of our investigation was to assess, on a clinical ground, the prognostic values of base excess in uncomplicated ST elevation myocardial infarction. Two considerations arises from this. Firstly, despite the universal controversy on the diagnostic power of different methodological approaches for the evaluation of acid-base disorders [1,2] (diagnostic target), the assessment of acidosis also retains a prognostic significance in different clinical settings [3-5] (prognostic target). In this context, recently, in acute myocardial infarction, anion gap (though its "diagnostic" limits) proved to provide important incremental information for initial risk stratification. In agreement with these findings, and despite the scarcity of data on acute cardiac patients on this topic, we documented that the presence of low base excess was an independent predictor for intra-ICCU complications (represented by acute pulmonary edema and arrhythmias) in uncomplicated ST elevation myocardial infarction submitted to percutaneous interventions. Secondly, the available literature dealing with the diagnostic significance of "acid-base parameters" stems mainly from studies in critically ill patients. A recent growing body of evidence [3-5] strongly supports the notion that $\mathrm{HCO}_{3}$, base excess and anion gap (corrected for hypoalbuminemia, when needed) remain the most appropriate for clinical usage. In our investigation we enrolled consecutive uncomplicated STEMI patients, mirroring the real world scenario. These patients do not show hypoalbuminemia and hence anion gap correction is not necessary. In our opinion, the strength of our investigation

C. Lazzeri $(\varangle) \cdot$ S. Valente $\cdot$ G. F. Gensini Intensive Cardiac Care Unit, Florence, Italy e-mail: lazzeric@libero.it is represented by the fact that easily available parameters (such as base excess) proved to help clinicians in optimizing risk stratification in the early phase of STEMI patients, even if uncomplicated. Like Dr Berend, we agree that $\mathrm{Cl} / \mathrm{Na}$ deserves further studies in a larger cohort of patients in order to better clarify its clinical significance since it is a very feasible parameter, and that is what we have expressed in the section "limit of the study".

We are very grateful for the suggestions and challenges posed by Dr Berend. Yet we are convinced that in the dialectic reasoning on acid-base evaluation, the clinical significance of parameters should also be taken into account, bearing in mind the recent evidence.

Conflict of interest None.

\section{References}

1. Doberer D, Funk GC, Kirchner K, Schneeweiss B (2009) A critique of Stewart's approach: the chemical mechanism of dilutional acidosis. Intensive Care Med 35(12):2173-2180

2. Boniatti MM, Cardoso PR, Castilho RK, Vieira SR (2009) Acidbase disorders evaluation in critically ill patients: we can improve our diagnostic ability. Intensive Care Med 35(8):1377-1382

3. Lazzeri C, Valente S, Chiostri M, Picariello C, Gensini GF (2010) Acid-base imbalance in uncomplicated ST elevation myocardial infarction: the clinical role of tissue acidosis. Intern Emerg Med 5:61-66

4. Fidkowski C, Helstrom J (2009) Diagnosing metabolic acidosis in the critically ill: bridging the anion gap, Stewart, and base excess methods. Can J Anaesth 56(3):247-256 Epub 2009 Feb 13

5. Dubin A, Menises MM, Masevicius FD, Moseinco MC, Kutscherauer DO, Ventrice E, Laffaire E, Estenssoro E (2007) Comparison of three different methods of evaluation of metabolic acid-base disorders. Crit Care Med 35(5):1264-1270 